DOI: $10.15593 / 2224-9354 / 2019.4 .20$

УДК 338.439

\title{
О.Я. Старкова
}

\author{
ИМПОРТОЗАМЕЩЕНИЕ \\ И РЕГИОНАЛЬНЫЙ РЫНОК ПРОДОВОЛЬСТВИЯ
}

\begin{abstract}
Определена роль импорта в процессе воспроизводства. Уточнены причины, по которым РФ попала в большую зависимость от импорта продовольствия. Рассмотрены условия, при которых проблема достижения продовольственной безопасности стала актуальной. Определены факторы, которые являются основой для достижения продовольственной независимости. Названы условия, при которых импортозамещение может стать реальным. Уточнена связь развития производительных сил и импортозамещения. Сопоставлены уровни государственной поддержки сельского хозяйства в РФ и зарубежных странах. Предпринята попытка выявить взаимосвязь между доходами населения и реализацией сельскохозяйственной продукции. Дана оценка существующих мнений о возможности превращения экономики России в экспортно ориентированную экономику. Названы результаты импортозамещения в аграрной сфере Пермского края. Проведен анализ производства продукции растениеводства и животноводства. Выявлено место хозяйств различных категорий в производстве сельскохозяйственной продукции. Проведен анализ источников финансовых ресурсов развития сельскохозяйственного производства. Определена роль государственной поддержки развития сельского хозяйства, в том числе за счет налоговой политики. Рассмотрена структура импорта Пермского края, определена доля импорта в продуктовых товарах и сельскохозяйственном сырье. Сделан вывод о сокращении импорта продовольственных товаров и сельскохозяйственного сырья из стран дальнего зарубежья при одновременном увеличении импорта данной продукции из стран СНГ. Проведен анализ ресурсов мяса и мясопродуктов, определена необходимость ввоза мяса в Пермский край. Проанализированы ресурсы молока и молокопродуктов. Определена актуальность импортозамещения в продуктовой сфере для Пермского края.

Ключевые слова: продовольственная безопасность, сельскохозяйственное сырье, продукция сельского хозяйства, растениеводство, животноводство.
\end{abstract}

Введение. Появление термина «импортозамещение» анализирует Е.В. Мезенцева, по мнению которой данное понятие появилось в середине прошлого века и обозначает политику развивающихся стран, стимулирующую индустриализацию путем протекционизма для защиты от импортеров [1, с. 102]. Импортозамещение - это политика замещения импортных товаров и услуг отечественными товарами и услугами, «которое осуществляется путем совершенствования существующих товарных позиций либо создания качественных и конкурентоспособных аналогов импортных товаров» [2, с. 155]. Некоторые авторы толкуют импортозамещение несколько шире, понимая под этим стремление обеспечить внутренний рынок на основе развития национального производства за счет протекционистской политики и поддержания

() Старкова 0.Я., 2019

Старкова Ольга Яковлевна - канд. экон. наук, доцент кафедры бухгалтерского учета и финансов ФГБОУ ВО «Пермский государственный аграрно-технологический университет имени Д.Н. Прянишникова», e-mail: klimova377@mail.ru. 
курса национальной валюты для предотвращения инфляции [3, с. 166]. Импорт выполняет, по мнению И. Иванова, важные функции в процессе воспроизводства и не только наполняет рынок товарами, которые в стране не производятся, но и привносит элементы конкуренции, противодействует монополизации, однако «излишек» импорта существенно тормозит процесс импортозамещения [4, с. 15]. Однако попытка РФ вписаться в мировую экономику с ее рыночными принципами привела к возросшей зависимости от импорта продовольствия [5, с. 53]. Экспорт и импорт продовольствия и сырья в России всегда имел отрицательное сальдо, но в 2016-2017 гг. этот разрыв сократился до 1,4 [6, с. 285]. Импортозамещение стало актуальной проблемой после того, как было принято решение о необходимости обеспечения продовольственной безопасности РФ [7, с. 71]. Представления о том, что не стоит вкладывать средства в развитие отечественного сельскохозяйственного производства, так как можно купить продовольствие за рубежом, тем более что в условиях высоких цен на энергоносители это было очень выгодно. Однако снижение цены на нефть и газ привело к появлению дефицита бюджета, снижению доходов предприятий и населения. Девальвация рубля вызвала удорожание импортного продовольствия, а экономические санкции делают вполне реальным сценарий, связанный с ограничением продажи для нашей страны необходимых продуктов и сельскохозяйственного сырья. Ускоренное импортозамещение для сохранения продовольственной безопасности Российской Федерации требует увеличения производства продовольствия [8, с. 87]. Для решения этого вопроса страна имеет необходимое количество земельных, водных и трудовых ресурсов, «что в сочетании с государственным протекционизмом и экономическим механизмом может обеспечить реализацию поставленных задач» [9, с. 24].

При этом можно согласиться с мнением В. Рязанова, который считает, что обеспечение импортозамещения не должно носить временно-конъюнктурного характера и должно быть рассчитано на перспективу [10, с. 4]. Чтобы импортозамещение стало реальным, требуется выполнение нескольких условий. Во-первых, развитие производительных сил, так как формирование первоклассных в технико-технологическом отношении производительных сил и импортозамещение - это двуединый процесс [10, с. 4]. Без внедрения новейших достижений науки и техники в воспроизводственный процесс (инновации в экономике) невозможно развитие сельскохозяйственного производства [11, с. 66]. Во-вторых, хотя государственная поддержка сельского хозяйства в Российской Федерации нарастает, тем не менее она существенно отстает от уровня, достигнутого в зарубежных странах. Так, государственные субсидии в РФ в расчете на 1 га сельскохозяйственных угодий составляют 10 долл. США, а в странах ЕС этот показатель за последние годы составил 300 долл. США [12, с. 10]. В-третьих, произведенная продукция должна 
иметь гарантированный спрос, однако в условиях кризиса и снижающихся доходов население вынуждено экономить, в том числе и на питании. Однако государство предполагает стимулировать потребление именно отечественных продуктов, в том числе и на уровне местных органов власти. Например, в соответствии с программой «Развитие сельского хозяйства и устойчивое развитие сельских территорий в Еловском муниципальном районе» Пермского края предполагалось увеличить долю сельскохозяйственной продукции местного производства в расходах населения с 11,5 \% в 2013 г. до 13 \% в 2016 г. $[13$, c. 80$]$.

Импортозамещение в АПК Е.О. Вахтерова, А.Р. Хайруллова и А.Г. Лобжания рассматривают с точки зрения функционального подхода, «как стратегию экономического развития отрасли по рационализации импорта путем стимулирования и поддержки отечественного производителя» [14, с. 136]. Для увеличения отечественного производства сельскохозяйственной продукции необходимо, как считает Т.Н. Литвинова, модернизировать рынок сельскохозяйственной техники [15, с. 136]. Кроме того, требуется диверсификация экономики России в целом, без чего решить проблему импротозамещения невозможно, считает В.Н. Махалин [16, с. 85].

В условиях товарных ограничений и девальвации отечественной валюты экономические агенты, работающие на продовольственном рынке, по мнению П.А. Бирюкова, «вынуждены переключаться на отечественные товары» $[17$, c. 45$]$.

Можно согласиться с мнением некоторых авторов (Г.И. Гакуш, Я.С. Ядгаров, В.А. Сидоров), которые предлагают не ограничиваться только импортозамещением, а идти дальше - к экспортно ориентированной экономике [18, с. 134]. Решение этих вопросов осуществляется в масштабах всей страны, но региональный аспект импортозамещения является наименее освещенным в экономической литературе. В данном исследовании предпринята попытка провести анализ импортозамещения и развития продовольственного рынка, на примере отдельно взятого региона.

Объекты и методы исследования. Объектом исследования является рынок продовольствия и сельскохозяйственного сырья Пермского края в условиях обеспечения импортозамещения. Использован монографический метод исследования, позволяющий применять комплексно-функциональный анализ для изучения взаимосвязей с помощью аналитических показателей.

Результаты и обсуждения. Пермский край хотя официально отнесен к территориям, где сельскохозяйственное производство осуществляется в наименее благоприятных условиях, но все-таки имеет по данным Пермстата, значительные объемы производства [19, с. 92].

Данные табл. 1 свидетельствуют о том, что за анализируемый период производство продукции сельского хозяйства в Пермском крае сократилось 
на 3,5 \%. При этом производство продукции животноводства сократилось на 229 млн руб., тогда как производство продукции растениеводства на 1359,9 млн руб. При этом можно отметить, что в 2016 г. по сравнению с 2015 г. продукция растениеводства выросла на 171,6 млн руб. В структуре производства преобладает продукция животноводческой отрасли.

Таблица 1

Производство продукции сельского хозяйства в Пермском крае, млн руб.

\begin{tabular}{|l|c|c|c|}
\hline \multicolumn{1}{|c|}{ Показатель } & 2015 г. & 2016 г. & 2017 г. \\
\hline Всего & 46537,0 & 46067,3 & 44956,4 \\
\hline В том числе: & & & \\
\hline растениеводство & 17970,3 & 18141,9 & 17749,6 \\
\hline животноводство & 28566,7 & 27925,4 & 27206,8 \\
\hline
\end{tabular}

На эффективность производства оказывает воздействие особенность его организации, связанная с использованием различных форм хозяйства. Производители сельскохозяйственной продукции представлены организациями, хозяйствами населения, крестьянскими (фермерскими) хозяйствами и индивидуальными предпринимателями (табл. 2)[19, с. 92].

Таблица 2

Продукция сельского хозяйства по категориям хозяйств

в Пермском крае, \%

\begin{tabular}{|l|c|c|c|}
\hline \multicolumn{1}{|c|}{ Показатель } & 2015 г. & 2016 г. & 2017 г. \\
\hline Хозяйства всех категорий & 100 & 100 & 100 \\
\hline Сельскохозяйственные организации & 53,4 & 50,5 & 53,7 \\
\hline Хозяйства населения & 42,5 & 44,6 & 40,4 \\
\hline $\begin{array}{l}\text { Крестьянские (фермерские) хозяйства, индивидуаль- } \\
\text { ные предприниматели }\end{array}$ & 4,1 & 4,9 & 5,9 \\
\hline
\end{tabular}

В соответствии с данными табл. 2 можно сделать вывод, что большая часть продукции сельского хозяйства в Пермском крае производится сельскохозяйственными организациями и доля их имеет тенденцию к росту. Доля в общем объеме продукции хозяйств населения с 2015 по 2017 г., напротив, сократилась на 2,1\%. Крестьянские (фермерские) хозяйства и индивидуальные предприниматели пока не вносят большого вклада в производство сельскохозяйственной продукции, но доля их за анализируемый период выросла на $1,8 \%$.

Рост объемов производства зависит от ряда факторов, и важнейший из них - наличие финансовых ресурсов у предприятий. В предыдущий период сельскохозяйственные производители не могли опираться на собственные средства в качестве источника развития, так как большинство предприятий были низкорентабельными или убыточными [20, с. 9]. В настоящее время 
финансовое положение предприятий улучшилось и в источниках инвестиций в основной капитал преобладают их собственные средства [17, с. 355]. Значительную поддержку сельскохозяйственным производителям оказывает государство, в том числе за счет снижения налогового бремени, применения специального налогового режима - единого сельскохозяйственного налога $[7$, c. 75]. Эти благоприятные условия позволяют надеяться на возможность достижения продовольственной безопасности.

Зависимость Пермского края от импортного продовольствия отражена в табл. $3[19$, с. 173].

Таблица 3

Состав импорта Пермского края, млн долл. США

\begin{tabular}{|l|c|c|c|c|}
\hline \multicolumn{1}{|c|}{ Показатель } & 2014 г. & 2015 г. & 2016 г. & 2017 г. \\
\hline Всего & 1071,3 & 672,3 & 713,8 & 676,9 \\
\hline $\begin{array}{l}\text { В том числе продуктовые товары } \\
\text { и сельскохозяйственное сырье }\end{array}$ & 11,9 & 15,5 & 20,2 & 23,1 \\
\hline
\end{tabular}

Анализируя показатели табл. 3, можно сделать вывод, что доля импортного продовольствия и сельскохозяйственного сырья в общем объеме импорта в Пермском крае очень незначительна. В условиях экономических санкций импорт в целом сократился на 36,8 \%, однако импорт продуктовых товаров и сельскохозяйственного сырья вырос с 11,9 млн долл. в 2014 г. до 23,1 млн долл. в 2017 г. Рассмотрим, как изменилась структура импорта продовольствия в зависимости от стран-импортеров (табл. 4).

Таблица 4

Импорт из стран дальнего зарубежья и стран СНГ

в Пермский край, млн долл. США

\begin{tabular}{|l|c|c|c|c|}
\hline \multicolumn{1}{|c|}{ Показатель } & 2014 г. & 2015 г. & 2016 г. & 2017 г. \\
\hline Импорт из стран дальнего зарубежья & 1000,9 & 553,5 & 602,1 & 542,0 \\
\hline $\begin{array}{l}\text { В том числе } \\
\text { продовольственные товары и сырье }\end{array}$ & 11,0 & 7,5 & 7,3 & 6,3 \\
\hline Импорт из стран СНГ & 70,4 & 118,8 & 111,7 & 134,9 \\
\hline $\begin{array}{l}\text { В том числе } \\
\text { продовольственные товары и сырье }\end{array}$ & 0,9 & 8,0 & 12,9 & 16,8 \\
\hline
\end{tabular}

Данные табл. 4 свидетельствуют о том, что импорт в Пермский край сократился за счет стран дальнего зарубежья, в то время как импорт из стран СНГ - вырос почти в два раза. Еще более показательным является изменение структуры импорта продовольственных товаров и сельскохозяйственного сырья: импорт из стран дальнего зарубежья сократился почти в два раза, импорт из сран СНГ вырос в 19 раз. Можно утверждать, что продуктовое эмбарго, введенное РФ в ответ на экономические санкции ряда западных стран, не 
привело к сокращению импорта продовольствия, изменилась лишь его структура, место продовольствия из стран дальнего зарубежья заняли товары из стран СНГ.

Незначительность продовольственного импорта, однако, не свидетельствует о том, что все продовольствие, потребляемое населением, произведено в данном регионе, так как часть необходимых продуктов завозится из других субъектов РФ. Рассмотрим формирование ресурсов мяса и мясопродуктов (табл. 5) [19, с. 99].

Таблица 5

Ресурсы мяса и мясопродуктов в Пермском крае, тыс. т

\begin{tabular}{|l|c|c|c|}
\hline \multicolumn{1}{|c|}{ Показатель } & 2015 г. & 2016 г. & 2017 г. \\
\hline Запасы на начало года & 12,5 & 10,5 & 10,0 \\
\hline Производство & 79,4 & 75,8 & 72,0 \\
\hline Ввоз, включая импорт & 116,3 & 109,4 & 131,6 \\
\hline И т о г о ресурсов & 208,2 & 195,7 & 213,6 \\
\hline
\end{tabular}

Данные табл. 5 свидетельствуют о том, что общий объем ресурсов мяса и мясопродуктов в Пермском крае за анализируемый период имел незначительные колебания: в 2016 г. по сравнению с 2015 г. объем снизился на 6 \%, а в 2017 г. по сравнению с 2016 г. вырос на 9,1 \%. Негативным фактом является снижение запасов на начало года, отмеченное и в 2016 и 2017 гг. Производство также снизилось с 79,4 тыс. т в 2015 г. до 72 тыс. т в 2017 г. В структуре ресурсов преобладает ввоз мяса и мясопродуктов, который в 2017 г. составил $62 \%$ от общего размера. За данный период ввоз увеличился на 15,3 тыс. т. В целом Пермский край обеспечен мясом и мясопродуктами собственного производства только 34-38 \%.

Обязательным в продуктовой корзине является наличие молочных продуктов. Насколько Пермский край обеспечен молоком, отражено в табл. 6 $[19$, с. 100$]$.

Таблица 6

Ресурсы молока и молокопродуктов в Пермском крае, тыс. т

\begin{tabular}{|l|c|c|c|}
\hline \multicolumn{1}{|c|}{ Показатель } & 2015 г. & 2016 г. & 2017 г. \\
\hline Запасы на начало года & 29,9 & 27,4 & 20,5 \\
\hline Производство & 482,3 & 483,5 & 487,5 \\
\hline Вво3, включая импорт & 362,7 & 189,5 & 187,0 \\
\hline И т о г о ресурсов & 874,9 & 700,4 & 695,0 \\
\hline
\end{tabular}

Размер ресурсов молока и молокопродуктов (см. табл. 6) имеют тенденцию к снижению: с 2015 по 2017 г. их общий объем сократился на 179,9 тыс. т (на 20,6 \%). Запасы молока на начало года также сократились на 9,4 тыс. т. Производство молока выросло весьма незначительно (на 5,2 тыс. т или на 
1,1%). Таким образом, главной причиной снижения ресурсов молока и молокопродуктов является почти двукратное сокращение ввоза, включая импорт, на 175,7 тыс. т. Зависимость рынка молока и молокопродуктов от ввоза из-за пределов Пермского края несколько меньшая, чем по мясу и мясопродуктам, что составило в 2017 г. 26,9\%.

Bbыводы. Таким образом, можно сделать вывод о том, что по основным продуктам питания (мясо, молоко) Пермский край находится в большой зависимости от ввоза из других регионов страны, так как доля собственного производства в общем объеме ресурсов колеблется от 27 до 70 \%. Такое большое количество завозимого продовольствия оказывает негативное воздействие на цены, которые увеличиваются из-за дополнительных транспортных расходов. Продовольственная безопасность Пермского края в целом снижается, так как подвоз продуктов питания может быть ограничен вследствие транспортных проблем или изменения экономической политики других регионов страны.

Импортозамещение в продовольственной сфере на первый взгляд кажется для Пермского края не актуальной проблемой, так как доля импортного продовольствия и сельскохозяйственного сырья не велика. Однако импорт в этом случае представлен не только деликатесными продуктами и экзотическими фруктами, но и семенами, материалом для искусственного осеменения сельскохозяйственных животных, т.е. тем, без чего невозможно осуществлять воспроизводственный процесс в аграрной сфере. Подобную зависимость необходимо преодолеть в самое ближайшее время, потому что возможное ограничение импорта подобного рода товаров может не только сдерживать развитие сельского хозяйства, но и подрывать продовольственную безопасность целого региона.

\section{Список литературы}

1. Мезенцева Е.В. Импортозамещение как фактор развития производственного потенциала региона // Известия Юго-Западного государственного университета. - 2016. - № 3(66). - С. 102-111.

2. Панферова Е.В. Импортозамещение в России: исторические аспекты и современные пути внедрения // Вестник Тульского филиала Финуниверситета. - 2016. - № 1. - С. 155-159.

3. Субхонбердиев А.Ш., Кулакова Д. Санкции и импортозамещение на продовольственном рынке России // Актуальные направления научных исследований XXI века: теория и практика. - 2016. - Т. 4 (24). - С. 166-170.

4. Иванов И. Импорт и импортозамещение в России // Мировая экономика и международные отношения. - 2012. - № 1. - С. 15-21.

5. Старкова О.Я. Инновационное развитие сельского хозяйства // Модернизация экономики и инновационное развитие России: векторы, пробле- 
мы, приоритеты: сб. науч. тр. I междунар. науч.-практ. конф. - Самара, 2016. - С. 52-56.

6. Белова Т.М. Процессы импортозамещения в аграрной сфере // Экономика региона. - 2019. - Т. 15, № 1. - С. 285-297.

7. Старкова О.Я. Налоговое бремя сельскохозяйственных предприятий // Пермский аграрный вестник. - 2014. - № 3(7). - С. 70-77.

8. Старкова О.Я. Конкуренция и государственная поддержка как условия развития аграрного сектора экономики // Пермский аграрный вестник. 2015. - № 1(9). - С. 88-91.

9. Гончаров В. Импортозамещение в продовольственном комплексе // Экономист. - 2015. - № 3. - С. 24-29.

10. Рязанов В. Импортозамещение и новая индустриализация России, или как преодолеть стагнацию экономики // Экономист. - 2014. - № 11. - С. 3-19.

11. Старкова О.Я. Государственное регулирование инновационного развития сельскохозяйственного производства // Пермский аграрный вестник. 2015. - № 3(11). - С. 65-69.

12. Шутьков А. Новый вектор российской аграрной политики - импортозамещение // АПК: экономика, управление. - 2015. - № 4. - С. 9-15.

13. Старкова О.Я. Сбалансированность бюджета как условие государственной поддержки сельского хозяйства // Экономика АПК Предуралья: ежегод. сб. науч. тр. - Пермь: Прокростъ, 2017. - С. 78-81.

14. Вахтерова Е.О., Хайруллова А.Р., Лобжания А.Г. Импортозамещение на основе обеспечения продовольственной безопасности России // Экономика и управление: новые вызовы и перспективы. - 2016. - № 10. - С. 136-140.

15. Литвинова Т.Н. Импортозамещение на российском рынке сельхозтехники: вызовы современности // Актуальные направления научных исследований XXI века: теория и практика. - 2016. - Т. 4, № 4 (24). - С. 136-138.

16. Махалин В.Н. Импортозамещение в условиях кризиса экономики России: финансовый аспект // Вестник Университета (Государственный университет управления). - 2016. - № 9. - С. 85-87.

17. Бирюков П.А. Импотозамещение в России: направления и устойчивость // Вестник Финансового университета. - 2016. - Т. 20, № 5(95). - С. 45-57.

18. Гакуш Г.И., Ядгаров Я.С., Сидоров В.А. Феномен рыночного хозяйства: опыт развития и новая экономическая реальность // Белорусский экономический журнал. - 2016. - № 2. - С. 131-141.

19. Пермский край в цифрах. 2018: крат. стат. сб. // Террит. орган Федер. службы гос. статистики по Пермскому краю. - Пермь, 2018. - 181 с.

20. Климова О. Инвестиционные ресурсы развития сельскохозяйственного производства // Экономика сельского хозяйства России. - 2004. № 10. - С. 9 . 


\section{References}

1. Mezentseva E.V. Importozameshchenie kak faktor razvitiia proizvodstvennogo potentsiala regiona [Import substitution as a development factor of region production potential]. Izvestiia Iugo-Zapadnogo gosudarstvennogo universiteta, 2016, no. 3(66), pp. 102-111.

2. Panferova E.V. Importozameshchenie $v$ Rossii: istoricheskie aspekty $\mathrm{i}$ sovremennye puti vnedreniia [Import substitution in Russia: Historical aspects and modern way of introduction]. Vestnik Tul'skogo filiala Finuniversiteta, 2016, no. 1, pp. $155-159$.

3. Subkhonberdiev A.Sh., Kulakova D. Sanktsii i improtozameshchenie na prodovol'stvennom rynke Rossii [Sanctions and import substitution in the food market of Russia]. Aktual'nye napravleniia nauchnykh issledovanii XXI veka: teoriia i praktika. 2016, vol. 4(24), pp. 166-170.

4. Ivanov I. Import i importozameshchenie v Rossii [Import and import substitution in Russia]. Mirovaia ekonomika i mezhdunarodnye otnosheniia, 2012, no. 1 , pp. 15-21.

5. Starkova O.Ia. Innovatsionnoe razvitie sel'skogo khoziaistva [Innovative development of agriculture]. Modernizatsiia ekonomiki i innovatsionnoe razvitie Rossii: vektory, problemy, prioritety. Proceedings of I Int. Sci.-Pract. Conf. Samara, 2016, pp. 52-56.

6. Belova T.M. Protsessy importozameshcheniia v agrarnoi sfere [The processes of import substitution in the agro-food sphere]. Ekonomika regiona, 2019, vol. 15, no. 1, pp. 285-297.

7. Starkova O.Ia. Nalogovoe bremia sel'skokhoziaistvennykh predpriiatii [Tax burden of agriculutral enterprises]. Permskii agrarnyi vestnik, 2014, no. 3(7), pp. $70-77$.

8. Starkova O.Ia. Konkurentsiia i gosudarstvennaia podderzhka kak usloviia razvitiia agrarnogo sektora ekonomiki [Competition and state aid as a condition for development of the agricultural sector]. Permskii agrarnyi vestnik, 2015, no. 1(9), pp. $88-91$.

9. Goncharov V. Importozameshchenie v prodovol'stvennom komplekse [Import substitution in the food complex of Russia]. Ekonomist, 2015, no. 3, pp. 24-29.

10. Riazanov V. Importozameshchenie i novaia industrializatsiia Rossii, ili kak preodolet' stagnatsiiu ekonomiki [Import substitution and the new industrialization of Russia, or how to overcome the economic stagnation]. Ekonomist, 2014, no. 11 , pp. 3-19.

11. Starkova O.Ia. Gosudarstvennoe regulirovanie innovatsionnogo razvitiia sel'skokhoziaistvennogo proizvodstva [State regulation of innovative development of agricultural production]. Permskii agrarnyi vestnik, 2015, no. 3(11), pp. 65-69. 
12. Shut'kov A. Novyi vektor rossiiskoi agrarnoi politiki - importzameshchenie [A new direction of Russian agricultural policy - import substitution]. APK: ekonomika, upravlenie, 2015, no. 4, pp. 9-15.

13. Starkova O.Ia. Sbalansirovannost' biudzheta kak uslovie gosudarstvennoi podderzhki sel'skogo khoziaistva [Balanced budget as a condition of government support for agriculture]. Ekonomika APK Predural'ia. Perm, Prokrost, 2017, pp. 78-81.

14. Vakhterova E.O., Khairullova A.R., Lobzhaniia A.G. Importozameshchenie na osnove obespecheniia prodovol'stvennoi bezopasnosti Rossii [Import substitution based on provision of food security in Russia]. Ekonomika $i$ upravlenie: novye vyzovy i perspektivy, 2016, no. 10, pp. 136-140.

15. Litvinova T.N. Importozameshchenie na rossiiskom rynke sel'khoztekhniki: vyzovy sovremennosti [Import substitution in the Russian agricultural machinery market: Modern challenges]. Aktual'nye napravleniia nauchnykh issledovanii XXI veka: teoriia i praktika, 2016, vol. 4, no. 4(24), pp. 136-138.

16. Makhalin V.N. Importozameshchenie $\mathrm{v}$ usloviiakh krizisa ekonomiki Rossii: finansovyi aspekt [Import substitution in the conditions of crisis of economy of Russia: Financial aspect]. Vestnik Universiteta (Gosudarstvennyi universitet upravleniia), 2016, no. 9, pp. 85-87.

17. Biriukov P.A. Importozameshchenie v Rossii: napravleniia i ustoichivost' [The import substitution in Russia: Trends and sustainability]. Vestnik Finansovogo universiteta, 2016, vol. 20, no. 5(95), pp. 45-57.

18. Gakush G.I., Iadgarov Ia.S., Sidorov V.A. Fenomen rynochnogo khoziaistva: opyt razvitiia i novaia ekonomicheskaia real'nost' [The phenomenon of market economy: Development experience and a new economic reality]. Belorusskii ekonomicheskii zhurnal, 2016, no. 2, pp. 131-141.

19. Permskii krai v tsifrakh. 2018: kratkii statisticheskii sbornik [Perm krai in numbers. 2018: A brief statistical book]. Perm, Territorial body of the Federal State Statistics Service for the Perm krai, 2018, $181 \mathrm{p}$.

20. Klimova O. Investitsionnye resursy razvitiia sel'skokhoziaistvennogo proizvodstva [Investment resources of the development of agricultural production]. Ekonomika sel'skogo khoziaistva Rossii, 2004, no. 10, p. 9.

Оригинальность $84 \%$

Получено 26.05.2019 Принято 26.06.2019 Опубликовано 15.01.2020 


\section{O.Ya. Starkova}

\section{IMPORT SUBSTITUTION AND REGIONAL FOOD MARKET}

The article defines the role of imports in the reproduction process. The reasons why Russia became highly dependent on food imports are clarified. The conditions are discovered under which the problem of achieving food security has become relevant. The factors ensuring food independence are identified. The relationship between the development of productive forces and import substitution is clarified. A comparison of the level of state support for agriculture in Russia and foreign countries is made. An attempt is made to identify the relationship between the incomes of the population and the sale of agricultural products. The assessment of the existing opinion on the possibility of transforming Russia into an export-oriented economy is given. The results of the import substitution efforts made by the Perm krai in the agricultural sphere are given. The analysis of crop and livestock production is carried out. The contribution of farms of different categories in the production of agricultural products is specified. The analysis of financial resources for the development of agricultural production is performed. The role of state support for the development of agriculture, including tax policy, is studied. The structure of imports of the Perm krai is considered, determining the share of imports in food products and agricultural raw materials. It is concluded that the import of food products and agricultural raw materials from foreign countries was dropping while the import of these products from the CIS countries was growing. The analysis of meat product sufficiency is performed; the necessity of meat import by the Perm krai is assessed. The resources of milk and dairy products are analyzed. The relevance of import substitution in the food sector for the Perm krai is determined.

Keywords: food security, agricultural raw materials, agricultural products, crops, livestock.

Olga Ya. Starkova - Candidate of Economic Sciences, Associate Professor, Department of Accounting and Finance, Perm State Agrarian and Technological University named after academician D.N. Pryanishnikov, e-mail: klimova377@mail.ru.

Received 26.05.2019 Accepted 26.06.2019 Published 15.01.2020 